\title{
Pengaruh variasi campuran arang dan biomassa terhadap waktu nyala, temperatur, dan karakteristik briket biopellet menggunakan kompor gasifikasi biomassa
}

\author{
Dedi Iskandar ${ }^{1}$, Kemas Ridhuan $^{2}$, Nurlaila Rajabiah ${ }^{3}$ \\ ${ }^{1}$ Prodi Teknik Mesin, Fakultas Teknik, Universitas Muhammadiyah Metro \\ Jl. Ki Hajar Dewantara 15 A Kota Metro, Lampung, Indonesia \\ 2,3Jurusan Teknik Mesin, Fakultas Teknik, Universitas Muhammadiyah Metro \\ Jl. Ki Hajar Dewantara 15 A Kota Metro, Lampung, Indonesia \\ *Corresponding author: kmsridhuan@yahoo.co.id
}

\begin{abstract}
Biopellet briquettes are fuels that are used as a substitute for fossil fuels for burning gasification stoves. The purpose of this study was to determine the mixture of charcoal and biomass in varying volumes, then formed biopellets. The method used by varying the mixture of coconut shell charcoal is $40 \%, 50 \%$, and $60 \%$. The types of biomass used are sawdust and rice husk, for the diameter of the top hole of the stove is $9.5 \mathrm{~cm}$, height is $25 \mathrm{~cm}$, inside is 16.8 $\mathrm{cm}$, outside is $20 \mathrm{~cm}$. The diameter of the biopellet briquettes is $5 \mathrm{~mm}$ and $20 \%$ adhesive is used. Based on the test results, variations in the composition of coconut shell charcoal affect the temperature and duration of the flame. The highest temperature of $713.2^{\circ} \mathrm{C}$ with a long flame of 26 minutes is found in a mixture of $60 \%$ charcoal and $40 \%$ sawdust biomass. While the lowest temperature is found in a mixture of $40 \%$ charcoal and rice husk with a temperature of $615.9^{\circ} \mathrm{C}$ with a long flame of 17 minutes. The characteristics of the biopellet briquettes are the highest water content of $7.96 \%$ from the variation of $40 \%$ coconut shell charcoal, $60 \%$ rice husk biomass. The highest ash content was $9.02 \%$ from the variation of $60 \%$ coconut shell charcoal and $40 \%$ rice husk biomass. The highest calorific value was obtained from the variation of $60 \%$ coconut shell charcoal with $40 \%$ sawdust biomass reaching 4,571.64 cal/g.
\end{abstract}

Keywords : Briquettes, Biomass, Gasification.

\begin{abstract}
Abstrak
Briket biopellet merupakan bahan bakar yang digunakan sebagai pengganti bahan bakar fosil pada pembakaran kompor gasifikasi. Tujuan dari penelitian ini mengetahui campuran arang dan biomassa yang di variasikan volumenya, kemudian dibentuk biopelet. Metode yang digunakan dengan memvariasikan campuran arang tempurung kelapa yaitu $40 \%, 50 \%$, dan $60 \%$. Jenis biomassa yang digunakan yaitu serbuk gergaji dan sekam padi, untuk diameter kompor bagian lubang atas yaitu $9,5 \mathrm{~cm}$, tinggi $25 \mathrm{~cm}$, bagian dalam $16,8 \mathrm{~cm}$, bagian luar 20 $\mathrm{cm}$. Diameter briket biopellet $5 \mathrm{~mm}$ dan $20 \%$ perekat yang digunakan. Berdasarkan hasil pengujian variasi komposisi arang tempurung kelapa berpengaruh terhadap temperatur serta lama nyala api. Temperatur tertinggi $713,2{ }^{\circ} \mathrm{C}$ dengan waktu lama nyala api 26 menit terdapat pada campuran arang $60 \%$ dan jenis biomassa serbuk gergaji $40 \%$. Sedangkan temperatur terendah terdapat pada campuran arang $40 \%$ dan sekam padi dengan temperatur $615,9{ }^{\circ} \mathrm{C}$ dengan waktu lama nyala api 17 menit. Karakteristik dari briket biopellet yaitu kadar air tertinggi sebesar 7,96 \% dari variasi arang tempurung kelapa $40 \%$ jenis biomassa sekam padi $60 \%$. Kadar abu tertinggi 9,02\% dari variasi arang tempurung kelapa $60 \%$ dan jenis biomassa sekam padi $40 \%$. nilai kalor tertinggi didapatkan dari variasi arang tempurung kelapa $60 \%$ dengan jenis biomassa serbuk gergaji $40 \%$ mencapai $4.571,64 \mathrm{kal} / \mathrm{g}$.
\end{abstract}

Kata Kunci : Briket, Biomassa, Gasifikasi. 


\section{Pendahuluan}

Semakin berkembangnya teknologi di dunia kususnya di Indonesia, semakin banyak pula masalah yang dihadapi. Permintaan energi yang terus menerus mengakibatkan masalah eksploitasi bahan bakar fosil yang tidak dapat diperbarui dengan jangka waktu yang singkat dan bila digunakan secara terus menerus tanpa kita mencari alternatif pengganti energi tersebut maka energi yang ada di perut bumi lama kelamaan akan habis. Dalam hal ini untuk mengganti atau mengurangi penggunaan bahan bakar fosil yaitu digunakan bahan bakar biomassa sebagai bahan bakar pengganti.

Salah satu pemanfaatan biomassa yaitu dengan menggunakan kompor gasifikasi yang telah dirancang khusus. Proses gasifikasi merupakan suatu proses dekomposisi termal dari bahan bakar organik melalui pemberian sejumlah panas dengan suplai oksigen terbatas. Waktu dan temperatur pembakaran dapat dipengaruhi oleh kualitas biomassa tersebut, apabila kadar air yang berlebih akan mengakibatkan lamanya proses pembakaran yang dilakukan. Kemudian aplikasi penggunaan kompor biomassa akan meningkatkan efisiensi pembakaran secara signifikan, peningkatan efisiensi ini berarti mengurangi juga polusi asap yang berbahaya bagi kesehatan dan penggunaan jumlah bahan bakar biomassa akan berkurang [1]. Selain itu juga peningkatan efisiensi dapat berdampak pada temperatur pembakaran dan juga berakibat pada waktu.

Bahan bakar dibuat dalam bentuk briket biopellet. Briket biopelet yang berasal dari biomassa dikonversi dan dapat dimanfaatkan sebagai bahan bakar menggunakan teknik densifikasi, teknik ini bertujuan untuk meningkatkan densitas dari bahan dan memudahkan penyimpanan serta pengangkutan. Konversi biomassa dapat menaikkan kalori per unit volume, mudah diangkut, mempunyai ukuran yang sama dari biopellet yang dihasilkan [2].

\section{Tinjauan Pustaka}

Energi terbarukan secara garis besar didefinisikan menjadi energi yang memiliki potensial sebagai energi yang mengalami pembaruan terus menerus, energi terbarukan merupakan energi yang sangat ramah lingkungan, tentunya tidak mencemari lingkungan maupun perubahan iklim akibat pemanasan global, seperti pada sumber energi lainnya, ini menjadi alasan penting mengapa energi terbarukan banyak dilirik untuk kemajuan dan sebagai pengganti bahan bakar fosil, keberadaan energi terbarukan seperti, energi surya, air, angin, biomasa juga bisa menjadi pertimbangan untuk pemanfaatannya, karena energi terbarukan juga memiliki keunggulan serta kekurangan yang perlu dipahami sebelum menggunakannya. Keunggulannya adalah tidak memberikan polusi, memiliki sifat pembaruan terus menerus, dan memiliki potensi yang cukup besar.

\section{Biomassa}

Biomassa merupakan salah satu jenis bahan bakar padat selain batubara. Biomassa terdiri atas beberapa komponen yaitu kadar air (moisture content), zat terbang/mudah menguap (volatile matter), karbon terikat (fixed carbon), dan abu (ash) [3]. Dalam Proses pengeringan akan menghilangkan moisture, devolatilisasi yang merupakan tahapan pirolisis akan melepaskan volatile, pembakaran arang melepaskan karbon terikat dan sisa pembakaran menghasilkan abu. Parameter penting lainnya dalam biomassa adalah kandungan nilai kalornya. Besarnya nilai kalor sangat tergantung dari komposisi zat-zat di atas. Semakin tinggi kandungan karbon terikat maka nilai kalornya semakin tinggi.

Jenis biomassa merupakan sumber energi yang dihasilkan dari sisa-sisa tumbuhan dan limbah organik lainnya. Selain itu biomassa dapat dimanfaatkan sebagai bahan bakar kompor gasifikasi dan dapat mengurangi penggunaan bahan bakar fosil. Berikut adalah beberapa jenis biomassa yang dapat dimanfaatkan sebagai bahan bakar yaitu: 


\section{a) Sekam padi}

Sekam padi merupakan sebuah kulit yang membungkus butiran beras, selain menjadi limbah sekam padi juga dapat dimanfaatkan sebagai bahan bakar pembuatan batu bata [4]. Abu sekam padi merupakan limbah dari hasil pembakaran dari sekam padi, pada pembakaran sekam padi semua komponen organik diubah menjadi gas karbondioksida $\left(\mathrm{CO}_{2}\right)$ dan air $\left(\mathrm{H}_{2} \mathrm{O}\right)$ dan tinggal abu yang merupakan komponen anorganik. Sebagian abu tersebut mengandung silika, sedikit logam oksida, dan karbon residu yang diperoleh dari pembakaran terbuka [5].

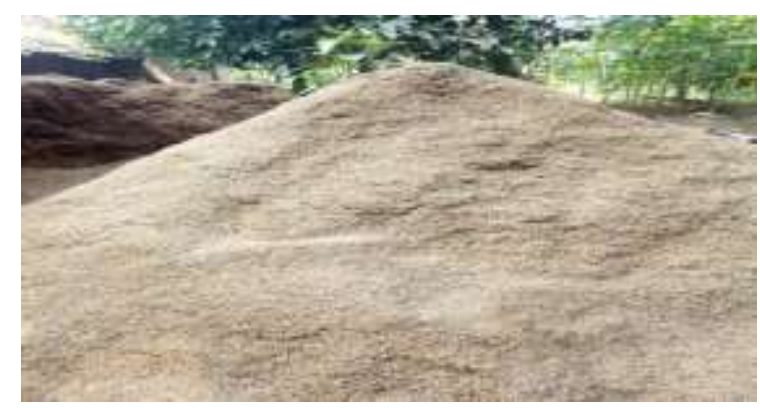

Gambar 1. Sekam Padi.

\section{b) Sebuk Gergaji}

Sebuk gergaji merupakan sisa-sisa hasil pemotongan kayu, hanya saja bentuk nya yang berbeda. Kayu merupakan sesuatu bahan yang diperoleh dari hasil pemotongan pohon-pohon di hutan, yang diambil sesuai kebutuhan. Di Indonesia ada tiga macam industri yang secara dominan mengkonsumsi kayu yang relatif besar yaitu: pengergajian, vinir atau kayu lapis, dan pulp atau kertas. Sejauh ini, limbah biomassa dari industri tersebut telah dimanfaatkan kembali sebagai bahan bakar guna melengkapi kebutuhan energinya [6].

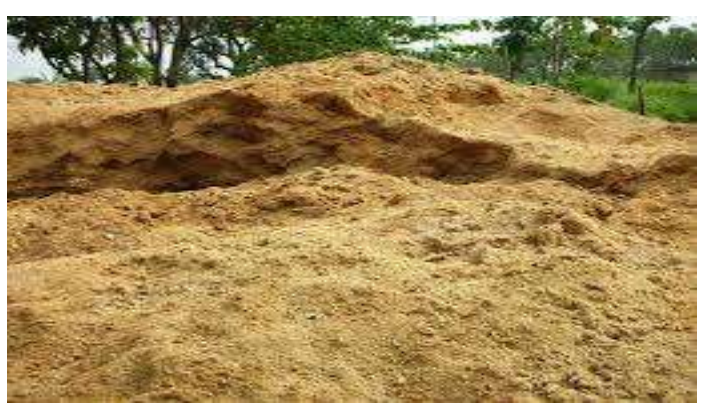

Gambar 2. Serbuk Gergaji. c) Arang

Arang merupakan suatu padatan berpori yang mengandung 85-95 \% karbon, dihasilkan dari bahan bahan yang mengandung karbon dengan pemanasan pada suhu tinggi. Ketika pemanasan berlangsung, diusahakan agar tidak terjadi kebocoran udara di dalam ruangan pemanasan sehingga bahan yang mengandung karbon tersebut hanya terkarbonisasi dan tidak teroksidasi selain sebagai bahan bakar arang juga dapat digunakan sebagai penyerap, daya serap ditentukan oleh luas permukaan partikel dan kemampuan ini dapat menjadi lebih tinggi terhadap arang tersebut jika dilakukan aktifasi dengan aktifator dengan bahan bahan kimia ataupun dengan pemanasan pada temperatur tinggi. Sehingga mengalami perubahan sifat sifat fisika dan kimia nya, arang yang disebut arang aktif [7].

\section{d) Biopelet}

Biopelet adalah salah satu bentuk bahan bakar alternatif terbentuk dari bahan organik terkompresi atau biomassa. Ada beberapa jenis bahan bakar pelet yang paling umum dan umumnya dibuat dari sebuk gergaji padat yang berasal dari limbah pemotongan kayu, limbah pembuatan mebel dan limbah lainya. Pellet ini dibuat dengan menghancurkan bahan baku dan dengan bantuan perekat biasanya tapioka, kemudian dilakukan pencetakan dengan alatnya yang bernama pellet mill. Biopellet dibuat dalam bentuk silinder dengan diameter $6-12 \mathrm{~mm}$ dan panjang 10-30 mm. Peletisasi adalah proses ekstrusi tipe pencetak termoplastik, dimana bahan biomassa diberikan gaya tekan oleh roller internal untuk dapat melewati cetakan silinder yang diam di eksternal ring yang berputar, dan menghasilkan padatan pelet. Kerapatan biomassa yang rendah menjadi meningkat, dari $40-250 \mathrm{~kg} / \mathrm{m}^{3}$ menjadi $600-800 \mathrm{~kg} / \mathrm{m}^{3}$ [8]. 
e) Gasifikasi

Teknologi gasifikasi merupakan proses dimana untuk meningkatkan daya guna yang terkandung dalam bahan biomassa melalui suatu proses dari bahan padat menjadi gas, proses ini berlangsung di dalam suatu alat yang disebut gasifer. Dalam alat ini dimasukkan bahan bakar untuk dibakar di dalam reaktor secara tidak sempurna. Dengan kata lain proses gasifikasi merupakan proses pembakarn persial bahan baku padat, melibatkan reaksi antara oksigen dengan bahan bakar padat. Lalu uap air dan karbon dioksida hasil pembakaran direduksi menjadi gas yang mudah tarbakar, yaitu karbon monoksida (CO), hydrogen $\left(\mathrm{H}_{2}\right)$, dan methan $\left(\mathrm{CH}_{4}\right)$. Gas-gas ini dapat dipakai sebagai pengganti BBM guna berbagai keperluan yang dibutuhkan [9].

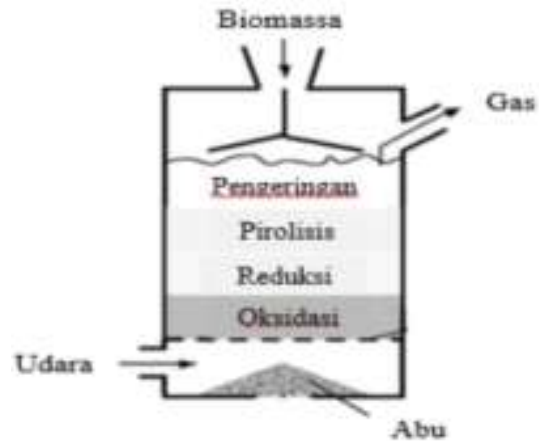

Gambar 3. Gasifikasi tipe up draft

Pembakaran yang sempurna akan menghasilkan tingkat konsumsi bahan bakar ekonomis dan berkurangnya besar kepekatan asap hitam gas buang karena pada pembakaran sempurna campuran bahan bakar dan udara dapat terbakar seluruhnya dalam waktu dan kondisi yang tepat [10].

\section{Metode Penelitian}

Dalam proses penelitian penulis melakukan uji bahan bakar untuk mendapatkan nilai dan data yang akurat. Dalam proses pengujiannya penulis menggunakan kompor gasifikasi tipe forced draft dengan bahan bakar briket biopellet yang divariasikan presentase jumlah arang dan biomassa.

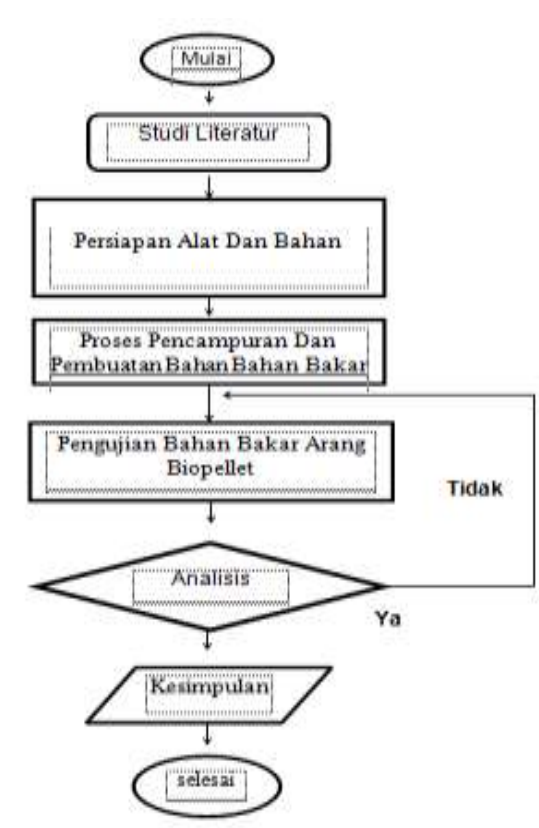

Gambar 4. Diagram Alir

Berdasarkan diagram alir dapat diketahui bahwa penelitian diawali dengan studi literatur dari sumber-sumber yang terkait dengan pembuatan dan pengujian briket biopellet dengan menggunakan kompor gasifikasi biomassa. Setelah melakukan observasi lalu menyiapkan alat dan bahan serta proses pencampuran bahan bakar setelah semua tercampur kemudian dicetak menggunakan alat sehingga terbentuk briket biopellet. Pengujian dilakukan dengan menggunakan kompor gasifikasi biomassa, penggujian dilakukan dengan menggunakan dua jenis campuran yaitu campuran biomassa serbuk gergaji dengan arang dan campuaran biamassa dengan sekam padi dan arang dengan menggunakan variasi $40 \%, 50 \%$, dan $60 \%$ campuran arang yang digunakan. Perekat yang digunakan sebanyak $20 \%$.

\section{Prosedur Penelitian}

Dalam penelitian ini dilakukan beberapa prosedur penelitian yaitu sebagai berikut:

a) Prosedur Pada Pembuatan Kompor Gasifikasi

1) Mengkaji dan melakukan tahap perencanaan dari segi desain dan bahan.

2) Setelah perencanaan dibuat matang, kemudian dilakukan proses 
pengerjaan atau pembuatan rangka gasifikasi.

3) Pada plat baja yang akan dibentuk menjadi silinder dan dipasang untuk bagian dinding luar dan bagian tabung bakar pada kompor gasifikasi.

4) Setelah rangka terbentuk dan dirangkai, lalu dipasangkan di komponen-koponen kompor gasifikasi seperti rotary fan, dan tabung beserta burner.

5) Kemudian dilakukan pengujian dan pengambilan data ketika semua komponen telah terpasang dan dapat digunakan sesuai dengan fungsinya dan ukuran.

b) Prosedur Pencampuran Biomassa

1) Menyiapkan alat dan bahan yang dibutuhkan dan akan digunakan seperti biomassa dan arang serta peralatan yang digunakan untuk mendukung campuran

2) Setelah bahan dan alat telah siap, kemudian dilakukan penakaran untuk biomassa dan arang yang akan dicampur menggunakan neraca atau timbangan .

3) Untuk biomassa seperti sekam padi akan dilakukan pencacahan agar ukurannya mudah untuk dilakukan pencampuran.

4) setelah didapatkan perbandingan yang akan digunakan untuk mencampur biomassa dan arang, maka selanjutnya biomassa akan dimasukkan ke wadah ataupun mangkuk untuk dilakukan percampuran

5) Lalu diaduk hingga rata biomassa dan arang dengan persentase komposisi yang ditentukan dan diberikan perekat menggunakan lem kayu

6) Campuran biomassa dan arang telah siap untuk dibentuk menjadi biopellet.
Tabel 1. Kompossi perbandingan arang dengan biopellet.

\begin{tabular}{|c|c|c|c|c|}
\hline \multirow[b]{2}{*}{ No } & \multirow[b]{2}{*}{$\begin{array}{c}\text { Komposisi } \\
\text { arang } \\
(\%)\end{array}$} & \multirow[b]{2}{*}{$\begin{array}{c}\text { Satua } \\
\mathrm{n} \\
(\mathrm{kg})\end{array}$} & \multicolumn{2}{|c|}{ Biomassa } \\
\hline & & & $\begin{array}{c}\text { Seka } \\
\text { m } \\
\text { padi } \\
(\mathrm{kg})\end{array}$ & $\begin{array}{l}\text { Serbuk } \\
\text { gergaji } \\
(\mathrm{kg})\end{array}$ \\
\hline 1 & 40 & 0,40 & 0,60 & 0,60 \\
\hline 2 & 50 & 0,50 & 0,50 & 0,50 \\
\hline 3 & 60 & 0,60 & 0,40 & 0,40 \\
\hline
\end{tabular}

Pada tabel 1, perbandingan antara komposisi yang diberikan dengan biomassa, dimaksudkan bahwa biomassa tidak dicampur dengan biomassa lain jadi biomassa sekam padi dengan arang sendiri dan serbuk gergaji dengan arang sendiri. Penelitian ini difokuskan untuk komposisi arang yang dicampur dengan biomassa jadi komposisi dari biomassa akan mengikuti komposisi arang yang diberikan dengan total campuran yang ditentukan adalah $1 \mathrm{~kg}$.

\section{Langkah Pengujian}

Langkah-langkah dalam pengujian ini dilakukan untuk mengetahui pengaruh yang diberikan dari komposisi campuran arang pada biomassa yang dibentuk menjadi arang biopellet yang digunakan sebagai bahan bakar kompor gasifikasi dan tujuannya untuk menggetahui seberapa besar pengaruh dari variasi komposisi arang sebanyak 40\%, 50\%, 60\% yang diberikan, terhadap suhu dan lama waktu pembakaran

\section{Hasil dan Pembahasan}

Pada penelitian ini akan dibahas data-data dan hasil yang didapatkan dalam pengujian dimana data yang diproleh saat proses pembuatan biopelet dan data yang diproleh saat pembakaran seta data yang diproleh dari hasil pengukuran dan perhitungan.

1. Pengaruh variasi campuran arang dengan jenis biomassa terhadap temperatur yang dihasilkan pada saat pembakaran.

Dalam pembahasan mengenai pengaruh yang didapatkan dari variasi campuran arang serta jenis biomassa pada 
temperatur pembakaran didapatkan hasil dimana dengan variasi campuran arang serta jenis biomassa yang diberikan akan menghasilkan perbandingan temperatur.

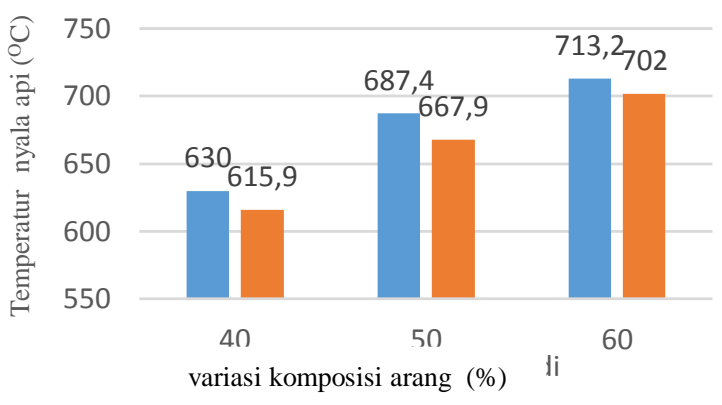

Gambar 5. Grafik perbandingan temperatur tertinggi.

Pada gambar 5, grafik perbandingan temperatur tertinggi menunjukkan bahwa jenis biomassa memiliki pengaruh namun perbedaan temperaturnya tidak terlalu jauh berbeda halnya dengan variasi dari komposisi arang dimana memiliki pengaruh yang sangat besar terhadap temperatur pembakaran. Semakin tinggi jumlah arang yang divariasikan maka termperatur akan semakin tinggi, hal ini disebabkan dari sifat arang yang nilai kalornya lebih tinggi, dan temperatur tertinggi didapatkan dengan nilai $713,2^{\circ} \mathrm{C}$ dari jenis biomassa serbuk gergaji dengan variasi campuran arang $60 \%$. Dan temperatur ini juga lebih tinggi dari temperatur yang dihasilkan dari pembakaran biomassa tanpa campuran.

2. Pengaruh variasi campuran arang dan jenis biomassa terhadap waktu pembakaran

Data dari pengujian mengenai variasi campuran arang terhadap waktu pembakaran juga didapatkan dimana campuran arang yang divariasikan juga menujukkan perbandingan dari waktu pembakaran, jadi variasi campuran arang dan jenis biomassa memiliki pengaruh yang besar terhadap waktu pembakaran.

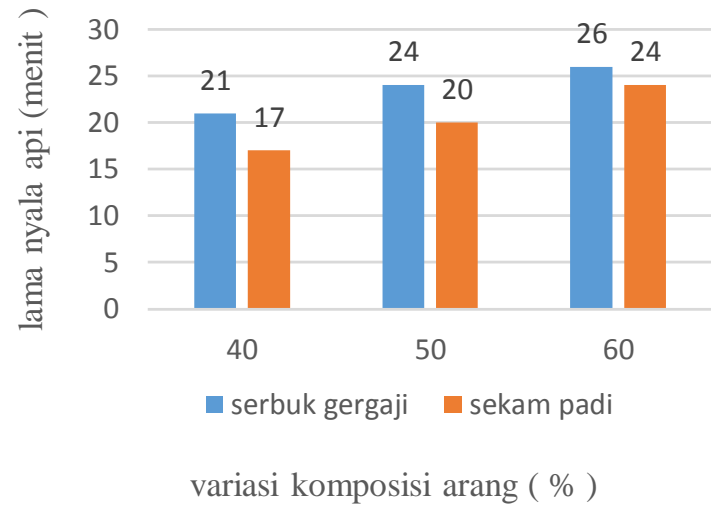

Gambar 6. Grafik perbandingan lama mampu nyala api pada tiap variasi

Dari gambar 6, grafik perbandingan lama mampu nyala api pada tiap varisi dapat dilihat bahwa variasi yang dilakukan pada komposisi campuran arang dan jenis biomassa memiliki pengaruh terhadap lama waktu dari nyala api hal ini dapat dijelaskan bahwa dengan semakin banyak komposisi arang pada biopellet maka sebagian besar biopellet adalah arang dengan begitu karena sifat arang yang padat namun mudah terbakar dan tahan lama jadi dengan dicampurnya jenis biomassa juga akan membuat biopellet lebih mudah terbakar dan tahan lama dan pada penelitian ini didapatkan waktu nyala api terlama adalah 26 menit dari variasi komposisi arang sebanyak $60 \%$ dan jenis biomassa serbuk gergaji.

Dari variasi campuran arang dengan jenis biomassa juga memiliki perbedaan dari biopellet yang dihasilkan dimana dari segi, tampilan didapatkan hasil perbandingan untuk tampilan dari biopellet yang didapatkan dari prngamatan dan analisa setelah pembuatan.

a) Hasil Briket Biopellet Dengan Campuran Biomassa Serbuk Gergaji

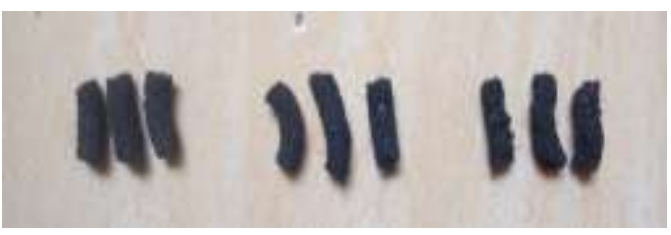

Gambar 7. Hasil Biopellet Arang Dan Biomassa Serbuk Gergaji. 
Pada gambar 7, hasil biopellet arang tempurung kelapa dengan jenis biomassa serbuk gergaji dapat dilihat bahwa komposisi arang dengan jenis biomassa memiliki pengaruh terhadap tampilan biomassa yang dihasilkan dimana semakin banyak komposisi arang yang diberikan maka tampilan akan semakin halus dan lebih padat dan dengan campuran biomassa serbuk gergaji biopellet yang dihasilkan juga tidak terlalu kasar.

b) Hasil Briket Biopellet Dengan Campuran Sekam Padi.

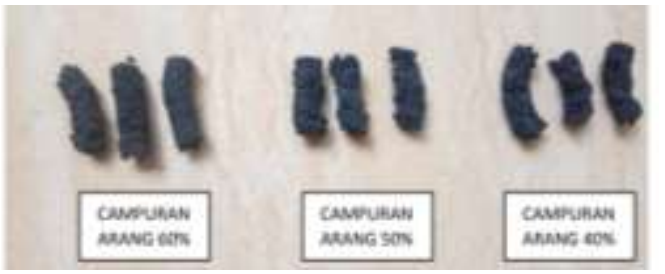

Gambar 8. Hasil Biopellet Arang Dan Biomassa Sekam Padi.

Dari gambar 8, hasil briket biopellet dari campuran biomassa sekam padi juga menghasilkan perbandingan dari segi tampilan dari briket biopellet yang dimana semakin besar komposisi arang tempurung kelapa tampilan biopellet yang dihasilkan juga lebih halus namun dengan digunakannya biomassa sekam padi hasil dari tampilan biopellet lebih kasar dibandingkan serbuk gergaji.

Karakteristik hasil pengujian laboratorium yaitu kadar air tertinggi sebesar 7,96\% dari variasi arang tempurung kelapa $40 \%$ jenis biomassa sekam padi $60 \%$. Kadar abu tertinggi 9,02\% dari variasi arang tempurung kelapa $60 \%$ dan jenis biomassa sekam padi $40 \%$. Kemudian untuk nilai kalor tertinggi yaitu $4.571,64 \mathrm{cal} / \mathrm{g}$ didapatkan dari variasi arang tempurung kelapa $60 \%$ dengan jenis biomassa serbuk gergaji $40 \%$.

\section{Kesimpulan}

Waktu nyala api terlama adalah 26 menit dari variasi komposisi arang sebanyak $60 \%$ dan jenis biomassa serbuk gergaji $40 \%$ dan waktu nyala api paling pendek didapatkan 17 menit dari variasi arang tempurung kelapa $40 \%$ dengan jenis biomassa sekam $60 \%$.

Temperatur tertinggi didapatkan dengan nilai $713,2{ }^{\circ} \mathrm{C}$ dari jenis biomassa serbuk gergaji $40 \%$ dengan variasi campuran arang 60\%. Dan temperatur terendah $615,9{ }^{\circ} \mathrm{C}$ didapatkan dari variasi arang tempurung kelapa $40 \%$ dengan jenis biomasa sekam padi $60 \%$. Abu hasil sisa pembakaran paling sedikit yaitu $0,102 \mathrm{~kg}$ pada variasi komposisi arang sebanyak $40 \%$ dengan jenis biomassa serbuk gergaji 60\%.dan abu sisa hasil pembakaran paling banyak adalah $0,26 \mathrm{~kg}$ dari variasi arang tempurung kelapa $60 \%$ dengan jenis biomassa sekam padi $40 \%$.

Karakteristik hasil pengujian laboratorium yaitu kadar air tertinggi sebesar 7,96\% dari variasi arang tempurung kelapa $40 \%$ jenis biomassa sekam padi $60 \%$. Kadar abu tertinggi 9,02\% dari variasi arang tempurung kelapa $60 \%$ dan jenis biomassa sekam padi $40 \%$. Kemudian untuk nilai kalor tertinggi yaitu 4.571,64 cal/g didapatkan dari variasi arang tempurung kelapa $60 \%$ dengan jenis biomassa serbuk gergaji $40 \%$.

\section{Referensi}

[1]. Pangala R.P, Tambunan H.A, Kartodiharjo H, Dan Pari G, 2016. Desain pengujian kinerja kompor gasifikasi-pirolisis. Jurnal Pengelolaan Sumber Daya Dan Lingkungan. No.1.Vol.6.Bogor.

[2] jufri M, Farosadid I, Mulyono M, mokhtar A, 2018. Analisis Variasi Temperatur Pengeringan Dan Persentase Perekat Terhadap Lama Waktu Pembakaran Biopellet Sekam Padi. Jurnal Prosiding SENTRA(Seminar Teknologi Dan Rekayasa). Malang.

[3] Syamsiro M, 2016. Peningkatan Kualitas Bahan Bakar Padat Biomassa Dengan Proses Dan Torefaksi. Jurnal 
Mekanika Dan Sistem Termal. No.1, Vol.1.

[4] Prasetya H.A. Dan Marlina P, 2013. Penggunaan Sekam Padi Sebagai Bahan Pengisi Dan Antioksidan Pada Pembuatan Kompon Karet. Jurnal Dinamika Penelitian Industri. No.2, Vol.24.

[5] Amaria, 2012. Adsorpsi Ion Sianida Dalam Larutan Menggunakan Adsorben Hibrida Aminoppropil Silika Gel Dari Sekam Padi T

[6] Vidian F, 2009. kompor gas berbahan bakar biomassa. Jurusan Jurnal Rekayasa Mesin Universitas Sriwijaya. No.2, Vol.9.

[7] Sembiring M.T, Dan Sinaga T.S, 2003. Arang Aktif (Pengenalan Dan Proses Pembuatanya). Jurusan Teknik Industri. Fakultas Teknik. Universitas Sumatra Utara

[8] Utarina L, 2019. Prospek Bahan Bakar Biopellet Sebagai Energi Alternatif Di Usaha Mikro Kecil Dan Menengah ( UMKM ). Karya Ilmiah. Jurusan Teknik Kimia. Politeknik Negri Sriwijaya Palembang.

[9] Rinovianto G, 2012. Karakteristik Gasifikasi Pada Updraft Double Gas Autlet Gasifer Mengnggunakan Bahan Bakar Kayu Karet. Fakultas Teknik. Departemen Teknik Mesin Depok.

[10] Djafar R, Djamalu Y, Halutis, Dan Botituhe, 2017. Analisis Performa Kompor Gasifikasi Biomassa Tipe Forced Dreft Menggunakan Fariasi Jumlah Bahan Bakar Tongkol Jagung. Jurnal Teknology Dan Entrepreneur. No 2. Vol. 5 